\title{
Beyond HLA system: non-HLA gene alleles of donor origin may influence risk of immune allo-HSCT complications
}

\author{
Alexey B. Chukhlovin \\ R. Gorbacheva Memorial Research Institute of Children Oncology, Hematology and Transplantology, The First St. Petersburg State \\ I. Pavlov Medical University, St. Petersburg, Russia
}

Prof. Alexey B.Chukhlovin, R. Gorbacheva Memorial Research Institute of Children Oncology, Hematology and Transplantation, The St. Petersburg State I. Pavlov Medical University, L. Tolstoy St. 6-8, 197022, St. Petersburg, Russia

\section{Summary}

This review article concerns genetic predisposal for some severe immune complications in allogeneic hematopoietic stem cell transplantation (allo-HSCT) which are mostly dependent on donor/recipient differences in the HLA set and on the so-called minor compatibility factors, e.g., certain HLA-G alleles and other immune-related proteins (TNF- $\alpha$, IL1- $\beta$, IL-2, -6, 10 and their receptors) associated with overall survival, graft rejection or acute graft-versus-host disease. Moreover, HSCT is a complex procedure with multiple cytotoxic agents used at conditioning therapy, and immunosuppressive drugs applied at different stages of posttransplant period. The minimal nucleotide differences in functionally active genes may cause sufficient changes in cell damage and recovery after HSCT. These polymorphic alleles could increase or diminish biological action of different enzymes, receptors, transporters, transcription factors etc. Therefore, distinct polymorphic gene alleles exhibiting high-or low-producing activities may be associated with major complications of HSCT and survival in HSC recipients.

Current studies on numerous effects of non-HLA gene polymorphisms in the donor/recipient pairs allowed us to make the following conclusions: 1) the majority of functionally active gene alleles controlling kinetics of cytotoxic drugs was mainly by recipient origin, normally being expressed in liver, spleen and target cells of blood system; 2) by contrary, gene alleles controlling immune factors (cytokines, their receptors etc.), associated with acute graft-versus-host disease were mostly, of donor origin, being more common than appropriate recipient alleles.

This donor predominance of allelic SNPs should be taken into account when planning haploidentical transplants and infusions of donor lymphoid cells in immunotherapy of tumors. For example, one may expect more expressed graft-versus-leukemia effect from the donor $\mathrm{T}$ cells exhibiting more active gene alleles (e.c., IL-6, IL$7 \mathrm{R}, \mathrm{MMP}-1$ et al.). Moreover, these protein products may be targeted by specific inhibitors to prevent excessive aGVHD.

\section{Keywords}

Hematopoietic stem cell transplantation, outcomes, functional gene polymorphisms, immune complications, pharmacokinetics. 


\section{Introduction}

Common complications, relapse rates and clinical outcomes in allogeneic hematopoietic stem cell transplantation (allo-HSCT) settings are primarily dependent on donor/recipient differences in HLA system. Highly complex polymorphic patterns of HLA genes at chromosome 6 are historically in focus of HSCT studies being carefully tested (Franca et al., 2015). In addition, gene variants of the so-called minor compatibility factors, e.g., certain HLA-G alleles and other immune-related proteins may be also associated with overall survival, graft rejection or acute graft-versus-host disease (Mullighan, Petersdorf, 2006). This list includes a series of well-known cytokines as TNF- $\alpha$, IL1- $\beta$, IL-2, -6, 10 and their receptors on target cell populations. Numerous polymorphisms were revealed in the genes encoding specific proteins (cytokines, chemokines and their receptors on target cells) active in immunity. The genes encoding foreign antigen-binding receptors (NOD2, TLR) and cell contact proteins may also exhibit functional polymorphisms.

Another class of non-MHC genes affecting HCT outcome is illustrated by the recent study by McCarroll et al (2009) showing that deletion of the entire UGT2B17 gene determining a numer of HLA gene alleles can result in an alloimmune response associated with aGvHD. This multi-center study (1345 patients) initially examined six common deletions (UGT2B17, UGT2B28, GSTT1, GSTM1, LCE3C and OR51A2) in a phase I discovery study using 414 HLA MRD transplants. The association of the UGT2B17 deletion with acute GVHD was validated in two additional cohorts of, resp., 336 and 595 HLA-identical sibling transplants. Risk of acute GVHD proved to be greater $(\mathrm{OR}=2.5)$ when donor and recipient were mismatched for homozygous deletion of UGT2B17.

Moreover, the KIR genetic region encodes variant receptors on NK cells, this cluster contains up to 15 genes, whose alleles can be identified by a variety of PCR methods. Acceptable genotyping must include typing for the known activating (2DS1, 2DS2, 2DS3, 2DS4, 2DS5, 3DS1) and inhibitory KIR genes (2DL1, 2DL2, 2DL3, 2DL5, 3DL1), in addition to the framework genes (3DL3, 2DL4, 3DL2). Now the KIR genes are subject to an in-depth biological association studies (Petersdorf et al., 2013).

In addition, a number of genes (mostly enzymes, and molecule transporters) control pharmacological effects of specific medications used for cytostatic chemotherapy and HSCT, e.g., during conditioning phase, and post-transplant (alkylating drugs, immunosuppressor agents, antibacterial antibiotics etc.). Common polymorphisms of these genes may alter biotransformation or drug transfer across cell membrane in liver (upon oral administration), other organs, or blood cell precursors, thus determining actual pharmacokinetics and individual dose effects of these drugs (Franca et al., 2015).

Some clinically relevant gene variants are located in gene promoter or other regulatory regions of the gene. Such high or low-producing alleles (indel mutations) simply change specific mRNA production levels, without altering specific protein structure. Meanwhile, nucleotide substitution in coding region of the gene may cause gain or loss of specific protein function (e.g., enzyme activity). Mutational shift of reading frame in coding region may cause loss of gene function or deficient production of intact protein in the cell.

Hence, minimal nucleotide differences in numerous functional genes may cause sufficient deviations of cell damage and recovery after HSCT. These polymorphic alleles could increase or diminish biological action of different enzymes, receptors, transporters, transcription factors etc. Therefore, distinct polymorphic gene alleles exhibiting high-or low-producing activities may be associated with major complications of HSCT and survival in HSC recipients.

Hence, even single functional gene polymorphisms may significantly influence the donor-recipient interplay and cause distinct risks for HSCT outcomes. Therefore, the aim of our comparative review was to summarize effects of some functional gene alleles of donor and recipient upon drug toxicity, incidence and severity of aGvHD and other tissue-specific complications post-transplant.

\section{Cytotoxic drug pharmacokinetics and GrHD depend on recipient genes}

Conditioning treatment with cytostatic drugs causes profound damage of mucosal epithelium (oral and intestinal mucositis), vascular endothelium (veno-occlusive hepatic disease), urothelium (hemorrhagic cystitis). Incidence and severity of these early complications, in particular, aGVHD, seem to depend on genetically altered transmembrane transport or biotransformation transformation (activation or conjugation) of busulfan, cyclophosphamide, and other cytotoxic drugs. A number of studies concerning genetic associations between pharmacokinetic parameters and GVHD occurrence were discussed by Franca et al. (2015). The workers reviewed several studies in pediatric transplantation and concluded that only few gene variants detected in HSC recipients could affect drug pharmacokinetics, e.g., $A B C B 1$ (pGp) gene for in vivo MTx concentrations; CYP3A upon CsA and Tacrolimus pharmacokinetics in plasma, whereas GST-A1, GST-P were associated with changed kinetics of oral Busulfan. Among a number of pharmacogenes, only genetic tests for CYP3A seemed to be recommended for wide clinical application in the patients undergoing chemotherapy. However, low- and high-producing variants of numerous genes and, especially, gene constellations may be determined pre-transplant, in order to adjust individual dosage of cytotoxic drugs and immune suppressors.

Our search in literature performed for different HSCT settings has also shown a clear dependence between drug transporter gene variants of a well-known methylene tetrahydrofolate reductase (MTHFR) polymorphism, and clinical GVHD post-transplant (Table 1). These modifying effects depended, mainly, on gene variants in recipients, except of an SLC19A1 gene variant (a folate transporter) in donor cells. Interestingly, Murphy et al. (2012) have shown a correlation between high-producer 677CC MTHFR in donor and GvHD severity. Meanwhile, SNPs of dihydrofolate reductase (DHFR) and solute carrier (SLC19A1) genes (both related to folate metabolism) in donors were associated with reduced risk of aGvHD, as shown by Laverdière et al. (2015). Hence, one may suggest that folate synthesis and its pharmacokinetics may depend on both recipient and donor gene variants. 
Table 1. Reported effects of pharmacologically relevant gene variants upon aGVHD incidence

\begin{tabular}{|c|c|c|c|c|}
\hline Gene, alleles & Clinical groups & $\begin{array}{l}\text { Clinical } \\
\text { parameters }\end{array}$ & Associations & Reference \\
\hline $\begin{array}{l}20 \text { genes related to } \\
\text { methotrexate and } \\
\text { cyclosporine metab- } \\
\text { olism }\end{array}$ & $\begin{array}{l}420 \text { HLA-matched } \\
\text { allo-HSCT recipi- } \\
\text { ent-donor pairs }\end{array}$ & $\begin{array}{l}\text { aGVHD (stage } \\
3-4), \text { cGVHD }\end{array}$ & $\begin{array}{l}\text { Recipient genes ABCC1 } \\
\text { (rs8058040), ABCC2 (rs3740065), } \\
\text { ATIC (rs2177735) are predictive for } \\
\text { grade III-IV aGVHD. } \\
\text { Donor dihydrofolate reductase } \\
\text { and SLC19A1 (folate transporter) } \\
\text { SNPs - reduced risk of severe } \\
\text { acute GVHD }\end{array}$ & $\begin{array}{l}\text { Laverdière et al., } \\
2015\end{array}$ \\
\hline $\begin{array}{l}\text { MTHFR SNPs, } 677 C>T \\
\text { and } 1298 A>C\end{array}$ & $\begin{array}{l}140 \text { allo-HSCT } \\
\text { patients and } \\
\text { donors }\end{array}$ & $\begin{array}{l}\text { 5-year survival, } \\
\text { aGvHD, and } 9 \\
\text { other outcomes }\end{array}$ & $\begin{array}{l}\text { Donor MTHFR 677CC genotype } \\
\text { was associated with earlier GVHD } \\
(P=.003) \text {, and more severe acute } \\
\text { GVHD (P = 0.02). }\end{array}$ & Murphy et al., 2012 \\
\hline MTHFR SNPs, 677C>T & $\begin{array}{l}107 \text { patients and } \\
\text { donors with leu- } \\
\text { kemia receiving } \\
\text { HSCT }\end{array}$ & $\begin{array}{l}\text { Oral mucositis } \\
(0 M), \text { hemor- } \\
\text { rhagic cystitis } \\
(\mathrm{HC}), \text { toxicity and } \\
\text { VOD of the liver, } \\
\text { aGvHD grade, } \\
\text { TRM and survival }\end{array}$ & $\begin{array}{l}\text { Recipient MTHFR polymorphisms } \\
\text { (C677T) were associated with } \\
\text { acute GvHD }\end{array}$ & Rocha et al., 2009 \\
\hline $\begin{array}{l}\text { 677TT genotype in } \\
\text { MTHFR gene }\end{array}$ & $\begin{array}{l}\text { MTHFR genotypes } \\
\text { in } 159 \text { recipients } \\
\text { and their donors }\end{array}$ & aGVHD & $\begin{array}{l}\text { Association between 677TT } \\
\text { genotype in recipient and a lower } \\
\text { incidence of grade I-IV acute } \\
\text { GVHD }\end{array}$ & $\begin{array}{l}\text { Sugimoto K. et al., } \\
2008\end{array}$ \\
\hline $\begin{array}{l}\text { IMPDHT SNPs IVS8- } \\
106 \mathrm{G}>\mathrm{A} \\
\text { (IMPDH=target } \\
\text { enzyme for mycophe- } \\
\text { nolate mofetil) }\end{array}$ & $\begin{array}{l}240 \text { allo-HSCT } \\
\text { recipients and } \\
\text { donors }\end{array}$ & aGvHD grade & $\begin{array}{l}\text { IVS8-106 G/G genotype in } \\
\text { recipients correlates with higher } \\
\text { aGVHD risk }\end{array}$ & Cao et al., 2012 \\
\hline $\begin{array}{l}\text { SNPs in ERalpha and } \\
\text { ERbeta genes }\end{array}$ & $\begin{array}{l}108 \text { patients } \\
\text { receiving a bone } \\
\text { marrow trans- } \\
\text { plant from an } \\
\text { HLA-matched } \\
\text { sibling donor }\end{array}$ & $\begin{array}{l}\text { aGVHD, overall } \\
\text { survival (OS) }\end{array}$ & $\begin{array}{l}\text { Recipient polymorphism for } \\
\text { Pvull-Xbal RFLP of ERalpha (intron } \\
\text { 1): occurrence of acute GVHD and } \\
\text { lower OS }\end{array}$ & $\begin{array}{l}\text { Middleton et al., } \\
2003\end{array}$ \\
\hline
\end{tabular}

Laverdière et al. (2015), when studying 420 recipient-donor pairs, have performed deep DNA sequencing of 20 candidate genes related to MTx and CsA metabolism and GvHD occurrence. Of them, only few genetic variants were significantly associated with acute GvHD risk. In particular, the risk was associated with genetic variations in recipients related to pharmacodynamic pathways of methotrexate and cyclosporine A, including methylenetetrahydrofolate reductase (MTHFR) rs2274976 and rs3737967, and 5-aminoimidazole-4-carboxamide ribonucleotide formyltransferase/ inosine monophosphate cyclohydrolase (ATIC, rs17514110) proved to be risk alleles (see Table 1). Similarly, donor SNPs in NFATC2 (molecular target of cyclosporine A) increased risk of worse prognosis. Meanwhile, single nucleotide polymorphisms of dihydrofolate reductase (DHFR) and solute carrier (SLC19A1) genes of donors (both related to folate metabolism) were associated with reduced risk of aGvHD.

Different types of clinical outcomes and appropriate pharmacogene correlations were also studied by Rocha et al. (2015). In 107 donor-recipient pairs, the authors studied allelic frequencies of the following genes: P450 cytochrome (CYP2B6), glutathione-S-transferase family (GST), multidrug-resistance gene (MDR gene), methylenetetrahydrofolate reductase (MTHFR) and vitamin D receptor (VDR). The endpoints, along with acute GvHD, were oral mucositis (OM), hemorrhagic cystitis (HC), toxicity and venoocclusive disease of the liver (VOD), transplantation-related mortality (TRM) and survival. Most effects of pharmacologically relevant recipient gene CYP2B6 (cyclophosphamide metabol- 
ic modification) were connected with acute therapy effects (oral mucositis, hemorrhagic cystitis). Recipient VDR TaqI showed correlations with TRM and overall survival. SNPs in estrogen receptor genes may also modify response to steroid hormone therapy. A study by Middleton (2003) has shown that an estrogen receptor alpha SNP (PvuII-XbaI) in recipient may affect both GvHD incidence and survival rates. All these association studies on SNPs and HSCT outcomes should be, however, reproduced in further works, oriented for search for appropriate candidate genes.

Despite certain evidence of associations between polymorphisms in genes encoding metabolizing enzymes (CYP3A4/3A5, UGT1A9) or drug transporters (ABCB1, ABCC2, SLCO1B1) and pharmacokinetics of several immunosuppressive drugs, diagnostic genotyping in order to calculate optimal initial dose for the patient is uncommon in clinical practice, probably due to absence of proof that clinical outcome is really improved when such genotyping was performed for the drug dosage. To the present time, clinical recommendations in relation to pharmacogenetic biomarkers exist only for CYP3A5 testing, in order to determine initial tacrolimus dose in patients (Pikard et al., 2016).

\section{Effects of donor gene SNPs upon immune response in acute GvHD:}

Acute GVHD is primarily caused by alloreactive donor lymphocytes which expand and migrate to the target tissues, mainly, skin and intestinal epithelium. aGVHD is an allo-aggressive inflammatory process triggered and regulated by multiple cytokines, and chemokines produced both by the host and donor cells. These gene variants may express highand low-producing activity thus modifying clinical course of aGVHD. These interactions are far from clearness, and are subject to many gene association studies.

Most factors studied in connection with GVHD risk are produced by innate immune cells (macrophages, neutrophils, natural killers etc.). To search effects of donor and recipient gene variants upon GVHD, we performed a selection of appropriate genetic associations in available literature (PubMed, keywords: GVHD, gene polymorphism). Included were the studies with positive associations found, where both recipients and their donors were genotyped. We asked whether donor, or host hyperactive genes (or both) are associated with aGvHD as the most life-threatening immune complication of allo-HSCT. The results are summarized in Table 2.

Table 2. Distinct effects of recipient and donor gene variants upon aGVHD

\begin{tabular}{|c|c|c|c|c|}
\hline Gene, alleles & Clinical groups & $\begin{array}{l}\text { Clinical } \\
\text { parameters }\end{array}$ & Associations & Reference \\
\hline \multicolumn{5}{|l|}{ GvHD enhanced } \\
\hline $\begin{array}{l}\text { TNFA-1031 (T>C), }-863 \\
(C>A),-857(C>T),-238 \\
(G>A), T N F B+252(A>C) \\
\text { and TNFRII codon } 196 \\
(T>C)\end{array}$ & $\begin{array}{l}138 \text { unrelated } \\
\text { donor/recipient } \\
\text { pairs underwent } \\
\text { allo-HSCT }\end{array}$ & $\begin{array}{l}\text { aGVHD } \\
\text { incidence and } \\
\text { severity }\end{array}$ & $\begin{array}{l}\text { TNFA- } 857 \text { C/C genotype in donors } \\
\text { and TNFB+252 } \mathrm{G} \text { allele-positive } \\
\text { recipients associated with } \\
\text { the development of grades II-IV } \\
\text { aGVHD. }\end{array}$ & Xiao et al., 2011 \\
\hline $\begin{array}{l}\text { IL-2 gene promoter, } \\
-330 \text { T>G SNP }\end{array}$ & $\begin{array}{l}95 \text { consecutive } \\
\text { donor and recipi- } \\
\text { ent pairs }\end{array}$ & $\begin{array}{l}\text { aGVHD } \\
\text { incidence }\end{array}$ & $\begin{array}{l}\text { At least one IL-2 G allele in recipient } \\
\text { of: twofold increased risk of acute } \\
\text { GVHD. }\end{array}$ & $\begin{array}{l}\text { MacMillan et al., } \\
2003\end{array}$ \\
\hline $\begin{array}{l}\text { Inflammation genes: } \\
259 \text { SNPs in } 53 \text { genes }\end{array}$ & $\begin{array}{l}268 \text { allo-HSCT } \\
\text { patients and } \\
\text { donors with } \\
\text { steroid-resistant } \\
\text { aGVHD and }\end{array}$ & $\begin{array}{l}\text { Severe aGVHD } \\
\text { (GIT affection) }\end{array}$ & $\begin{array}{l}\text { Donor genotypes: IFNG (rs2069727) } \\
\text { and IL6 (rs1800797) suggest higher } \\
\text { HVHD risk }\end{array}$ & Alam et al., 2015 \\
\hline $\begin{array}{l}\text { IL-6 -174 G>C polymor- } \\
\text { phism }\end{array}$ & $\begin{array}{l}\text { Seven cohort } \\
\text { studies, (1287 } \\
\text { recipient and } \\
\text { donor pairs) }\end{array}$ & $\begin{array}{l}\text { aGVHD risk } \\
\text { and severity }\end{array}$ & $\begin{array}{l}\text { Donors with IL-6 G allele: more } \\
\text { frequent grade I-IV aGVHD and grade } \\
\text { II-IV aGVHD }\end{array}$ & Choi et al., 2012 \\
\hline $\begin{array}{l}\text { Meta-analysis }(n=41) \\
\text { and own data on } 16 \text { in- } \\
\text { formative SNPs linked } \\
\text { to aGVHD }\end{array}$ & $\begin{array}{l}1424 \text { matched } \\
\text { donor-recipient } \\
\text { pairs after } \\
\text { allo-HSCT (MAC), } \\
\text { patient and } \\
\text { donor SNPs } \\
\text { genotyped or } \\
\text { imputed }\end{array}$ & $\begin{array}{l}\text { aGVHD stages } \\
\text { associated } \\
\text { with SNPs }\end{array}$ & $\begin{array}{l}\text { IL6 rs1800795 in donor were } \\
\text { associated with higher risk for } \\
\text { moderate/severe aGVHD; }\end{array}$ & Chien et al. (2012) \\
\hline
\end{tabular}




\begin{tabular}{|c|c|c|c|c|}
\hline Gene, alleles & Clinical groups & $\begin{array}{l}\text { Clinical } \\
\text { parameters }\end{array}$ & Associations & Reference \\
\hline IL1 $\beta+354$ allele & $\begin{array}{l}58 \text { consecutive } \\
\text { allo-HSCT recip- } \\
\text { ients and their } \\
\text { donors }\end{array}$ & $\begin{array}{l}\text { GVHD, ILI } \\
\text { in blood and } \\
\text { saliva }\end{array}$ & $\begin{array}{l}\text { Association between aGVHD, donor } \\
\text { IL1 } \beta \text { genotype, and high IL-1 } \beta \text { levels } \\
\text { in saliva }\end{array}$ & $\begin{array}{l}\text { Resende et al., } \\
2013\end{array}$ \\
\hline $\begin{array}{l}\text { IL-7Ro: rs1494555 and } \\
\text { rs1494558 SNPs }\end{array}$ & $\begin{array}{l}590 \text { recipient/ } \\
\text { donor pairs HLA- } \\
\text { MUD HCT }\end{array}$ & $\begin{array}{l}\text { GVHD and } \\
\text { TRM }\end{array}$ & $\begin{array}{l}\text { Donor SNPs: IL-7Ro: rs1494555GG } \\
\text { and rs1494558TT are associated with } \\
\text { aGvHD and cGivHD. }\end{array}$ & Shamim et al., 2013 \\
\hline $\begin{array}{l}\text { SNPs in } 13 \text { cytokine } \\
\text { genes }\end{array}$ & $\begin{array}{l}\text {.... Patients and } \\
\text { donors }\end{array}$ & aGVHD & $\begin{array}{l}\text { Donor SNPs: IL-4Ra and IL-12, } \\
\text { Recipient IL-l } \alpha-889 / C \text { allele showed } \\
\text { significant association with aGVHD }\end{array}$ & $\begin{array}{l}\text { Noori-Daloii et al., } \\
2013\end{array}$ \\
\hline $\begin{array}{l}\text { IL-17 rs2275913 197A } \\
\text { SNP }\end{array}$ & $\begin{array}{l}438 \text { pairs of } \\
\text { patients and } \\
\text { their unrelated } \\
\text { donors }\end{array}$ & $\begin{array}{l}\text { aGvHD, IL-17 } \\
\text { secretion by } \\
\text { T cells }\end{array}$ & $\begin{array}{l}\text { Donor IL-17 197A allele associated } \\
\text { with a higher risk of aGVHD }\end{array}$ & $\begin{array}{l}\text { Espinoza et al. } \\
\text { (2011) }\end{array}$ \\
\hline $\begin{array}{l}\mathrm{IL}-10-1082 \mathrm{G}>\mathrm{A}_{1}-819 \\
\mathrm{C}>\mathrm{T}_{1}-592 \mathrm{C}>\mathrm{A} \text { SNPs }\end{array}$ & $\begin{array}{l}11 \text { studies with } \\
3588 \text { recipients } \\
\text { and } 3221 \text { donors }\end{array}$ & $\begin{array}{l}\text { aGvHD risk } \\
\text { and severity }\end{array}$ & $\begin{array}{l}\text { Donors with an IL-10 - } 819 \text { CC } \\
\text { genotype: more frequent grade I-IV } \\
\text { aGVHD; recipients with IL- } 10-592 \text { CC } \\
\text { higher risk for grade II-IV aGVHD }\end{array}$ & Cho et al., 2015 \\
\hline $\begin{array}{l}\text { Meta-analysis }(n=41) \\
\text { and own data on } 16 \text { in- } \\
\text { formative SNPs linked } \\
\text { to aGVHD }\end{array}$ & $\begin{array}{l}1424 \text { matched } \\
\text { donor-recipi- } \\
\text { ent pairs after } \\
\text { allo-HSCT (MAC), } \\
\text { patient and } \\
\text { donor SNPs } \\
\text { genotyped or } \\
\text { imputed }\end{array}$ & $\begin{array}{l}\text { aGVHD stages } \\
\text { associated } \\
\text { with SNPs }\end{array}$ & $\begin{array}{l}\text { IL10 SNPs (rs1800871 and rs1800872) } \\
\text { in recipient associated with } \\
\text { decreased aGVHD risk }\end{array}$ & Chien et al. (2012) \\
\hline $\begin{array}{l}\text { IL-10 and IL-10Rbeta } \\
\text { gene SNPs }\end{array}$ & $\begin{array}{l}309 \text { HLA-identical } \\
\text { sibling donor and } \\
\text { recipient pairs }\end{array}$ & aGVHD, cGVHD & $\begin{array}{l}\text { Difference in IL-10 genotypes be- } \\
\text { tween patient and donor combined } \\
\text { with recipient IL-10Rbeta A/A geno- } \\
\text { type predisposed to acute GvHD, and } \\
\text { protected against chronic GvHD }\end{array}$ & Sivula et al., 2009 \\
\hline $\begin{array}{l}38 \text { SNPs in } 19 \text { immuno- } \\
\text { regulatory genes }\end{array}$ & $\begin{array}{l}\text { Pediatric HSCT } \\
\text { setting }\end{array}$ & $\begin{array}{l}\text { aGVHD } \\
\text { severity }\end{array}$ & $\begin{array}{l}\text { Three donor SNPs: IL10-1082GG, and } \\
\text { TLR4-3612TT with aGVHD: grade III-IV, } \\
\text { donor IL10-1082GG, and Fas-670CC } \\
+ \text { + CT, recipient IL18-607 TT + TG } \\
\text { genotypes: association with aGvHD } \\
\text { grades II-IV }\end{array}$ & Masetti et al., 2015 \\
\hline $\begin{array}{l}\text { NOD2 polymorphisms: } \\
3 \text { SNPs }\end{array}$ & $\begin{array}{l}464 \text { recipient- } \\
\text { donor pairs, } \\
\text { ATG-treated }\end{array}$ & $\begin{array}{l}\text { Risk of } \\
\text { infections and } \\
\text { severe aGVHD }\end{array}$ & $\begin{array}{l}\text { Donor N0D2 SNP8 constitutes a risk } \\
\text { factor of severe aGVHD }\end{array}$ & Jaskula et al., 2014 \\
\hline N0D2/CARD15 SNPs & $\begin{array}{l}342 \text { unrelated } \\
\text { transplants: } \\
\text { recipients+ } \\
\text { donors }\end{array}$ & $\begin{array}{l}\text { aGvHD risk, } \\
\text { overall sur- } \\
\text { vival }\end{array}$ & $\begin{array}{l}\text { Donor NOD2 SNP13 is a risk factor for } \\
\text { GvHD III/IV and survival }\end{array}$ & Holler et al., 2008 \\
\hline $\begin{array}{l}\text { TLR9 (T1237C; T1486C), } \\
\text { IL23R (A1142G), and } \\
\text { NOD2 SNP8 (R702W), } \\
\text { SNP12 (G908R) and } \\
\text { SNP13 (1007fs) }\end{array}$ & $\begin{array}{l}142 \text { AML patients } \\
\text { after non-T- } \\
\text { cell-depleted } \\
\text { myeloablative } \\
\text { allo-HSCT from } \\
\text { HLA-matched } \\
\text { sibling donors }\end{array}$ & $\begin{array}{l}\text { Overall sur- } \\
\text { vival, 5-year } \\
\text { mortality, } \\
\text { aGVHD }\end{array}$ & $\begin{array}{l}\text { Recipients with NOD2 gene variants: } \\
\text { higher risk for acute GVHD grade } \\
\text { III-IV }\end{array}$ & $\begin{array}{l}\text { Elmaagacli et al., } \\
2011\end{array}$ \\
\hline
\end{tabular}




\begin{tabular}{|c|c|c|c|c|}
\hline Gene, alleles & Clinical groups & $\begin{array}{l}\text { Clinical } \\
\text { parameters }\end{array}$ & Associations & Reference \\
\hline $\begin{array}{l}\text { Codons } 10 \text { and } 25 \text { of } \\
\text { TGFB1 }\end{array}$ & $\begin{array}{l}427 \text { myeloabla- } \\
\text { tive-conditioned } \\
\text { transplanted } \\
\text { patients }\end{array}$ & $\begin{array}{l}\text { aGVHD, NRM, } \\
\text { overall sur- } \\
\text { vival }\end{array}$ & $\begin{array}{l}\text { Recipient's genotype of TGFBI:grades } \\
\text { II-IV associated with increased aGVHD }\end{array}$ & Berro et al., 2010. \\
\hline $\begin{array}{l}\text { TGF-betal codon } 25 \\
\text { G/C polymorphism } \\
\text { (rs:1800471) }\end{array}$ & $\begin{array}{l}86 \text { patients after } \\
\text { BMT from HLA- } \\
\text { matched siblings }\end{array}$ & aGVHD & $\begin{array}{l}\text { Recipients with the TGF-GG gen- } \\
\text { otype: severe aGVHD significantly } \\
\text { more common than with CC or } \mathrm{GC} \text { set }\end{array}$ & $\begin{array}{l}\text { Rashidi-Nezhad et } \\
\text { al., } 2010\end{array}$ \\
\hline CTLA-4 SNPS & $\begin{array}{l}312 \text { donor-recipi- } \\
\text { ent pairs }\end{array}$ & $\begin{array}{l}\text { aGVHD, regi- } \\
\text { men toxicity }\end{array}$ & $\begin{array}{l}\text { Recipient } C T 60 G>A[G G] \text { genotype, } \\
\text { were independent aGvHD risk factors }\end{array}$ & $\begin{array}{l}\text { Karabon L et al, } \\
2015\end{array}$ \\
\hline $\begin{array}{l}3 \text { CTLA-4 gene poly- } \\
\text { morphisms }\end{array}$ & $\begin{array}{l}72 \text { thalassemia } \\
\text { patients and } \\
\text { their unrelated } \\
\text { donors }\end{array}$ & $\begin{array}{l}\text { aGVHD and } \\
\text { other out- } \\
\text { comes }\end{array}$ & $\begin{array}{l}\text { Recipient association and CT60-AA, } \\
\text { and onset of grade II-IV and grade } \\
\text { III-IV aGVHD. Recipient association: } \\
\text { for the 88-bp allele of the CTLA-4 } \\
\text { (AT)n SNP }\end{array}$ & Orrù Set al., 2012 \\
\hline $\begin{array}{l}\text { CTLA-4 alleles and } \\
\text { haplotypes for the } \\
-318 \mathrm{~T}>\mathrm{T} \text { and the } 49 A>G \\
\text { SNPS }\end{array}$ & $\begin{array}{l}112 \text { patients and } \\
\text { their sibling do- } \\
\text { nors in allo-HSCT } \\
\text { (Tunis) }\end{array}$ & Chronic GVHD & $\begin{array}{l}\text { Donor CTLA-4 -318C49G haplotype } \\
\text { may be a significant risk factor for } \\
\text { developing chronic GVHD }\end{array}$ & Sellami et al., 2011 \\
\hline $\begin{array}{l}\text { SNPs in M0RC4, CD14, } \\
\text { TLR4, N0D2, SLC22A4, } \\
\text { SLC22A5, CARD8, } \\
\text { NLRP3, and CLDN2 }\end{array}$ & $\begin{array}{l}\text {.... Donors, recipi- } \\
\text { ents, allo-HSCT }\end{array}$ & $\begin{array}{l}\text { Overall sur- } \\
\text { vival, aGVHD, }\end{array}$ & $\begin{array}{l}\text { Recipient allele CD14 (rs2569190): } \\
\text { associated with aGVHD }\end{array}$ & Norén et al., 2016 \\
\hline $\begin{array}{l}\text { SNPs in CD28, inducible } \\
\text { co-stimulator, CTLA4, } \\
\text { granzyme B, Fas and } \\
\text { Fas ligand }\end{array}$ & $\begin{array}{l}240 \text { pairs of } \\
\text { recipients and } \\
\text { donors MUD }\end{array}$ & $\begin{array}{l}\text { GVHD, sur- } \\
\text { vival, relapse } \\
\text { risk }\end{array}$ & $\begin{array}{l}\text { Unrelated donors with granzyme B } \\
+55 \text { genotype (AA): a risk factor for } \\
\text { grades II-IV aGVHD }\end{array}$ & Xiao et al., 2012 \\
\hline MMP-1 -1607 SNP & $\begin{array}{l}111 \text { donors and } \\
\text { recipients }\end{array}$ & aGVHD risk & $\begin{array}{l}\text { Donor MMP 2G/2G: associated with } \\
\text { aGVHD stage I-IV }\end{array}$ & $\begin{array}{l}\text { Chukhlovin et al., } \\
2003\end{array}$ \\
\hline $\begin{array}{l}\text { MADCAM1 rs2302217 AA } \\
\text { genotype }\end{array}$ & $\begin{array}{l}87 \text { HLA-matched } \\
\text { allo-HSCT recip- } \\
\text { ients and their } \\
\text { donors }\end{array}$ & $\begin{array}{l}\text { aGVHD, cGVHD } \\
\text { occurence }\end{array}$ & $\begin{array}{l}\text { Recipients with MADCAM1 rs2302217 } \\
\text { AA homozygosity had more common } \\
\text { aGVHD and cGVHD }\end{array}$ & $\begin{array}{l}\text { Ambruzova et al., } \\
2009 .\end{array}$ \\
\hline $\begin{array}{l}\text { VDR Apal, Taql and } \\
\text { Fokl alleles }\end{array}$ & $\begin{array}{l}123 \text { Polish recip- } \\
\text { ients and their } \\
\text { donors }\end{array}$ & $\begin{array}{l}\text { aGVYD risk, } \\
\text { death risk }\end{array}$ & $\begin{array}{l}\text { Two donor SNPs Apal AA and Fokl FF } \\
\text { significantly contributed to grade } \\
\text { II-IV aGVHD }\end{array}$ & $\begin{array}{l}\text { Bogunia-Kubik et } \\
\text { al., } 2008\end{array}$ \\
\hline \multicolumn{5}{|c|}{ GvHD-protective alleles } \\
\hline $\begin{array}{l}\text { IL-10 and IL-10Rbeta } \\
\text { gene SNPs }\end{array}$ & $\begin{array}{l}309 \text { HLA-identical } \\
\text { sibling donor and } \\
\text { recipient pairs }\end{array}$ & aGVHD, cGVHD & $\begin{array}{l}\text { Difference in genotypic IL-10 be- } \\
\text { tween patient and donor combined } \\
\text { with recipient IL-10Rbeta A/A geno- } \\
\text { type protected against chronic GvHD }\end{array}$ & Sivula et al., 2009 \\
\hline $\begin{array}{l}\text { IL-10 promoter }-1082, \\
-819 \text { and }-592 \text {, their } \\
\text { haplotypes }\end{array}$ & $\begin{array}{l}57 \text { pediatric } \\
\text { allo-HSCTs (MAC), } \\
\text { both recipients } \\
\text { and donors }\end{array}$ & $\begin{array}{l}\text { aGvHD, TRM, } \\
\text { OS }\end{array}$ & $\begin{array}{l}\text { Recipients with IL-10 promoter } \\
\text { GCC haplotypes showed lower risk of } \\
\text { severe aGVHD and TRM }\end{array}$ & $\begin{array}{l}\text { Goussetis et al., } \\
2011\end{array}$ \\
\hline $\begin{array}{l}\text { IL-10 promoter gene } \\
\text { SNPs }\end{array}$ & $\begin{array}{l}\text { PubMed and Em- } \\
\text { base databases } \\
\text { and } 10 \text { studies }\end{array}$ & aGVHD & $\begin{array}{l}\text { Positive correlation between the } \\
\text { - } 592 \mathrm{AA} \text { homozygote and - } 1082 \mathrm{~A} \text { allele } \\
\text { in recipient: lower risk of severe } \\
\text { aGvHD in HSCT }\end{array}$ & Zhu et al., 2013 \\
\hline
\end{tabular}




\begin{tabular}{|c|c|c|c|c|}
\hline Gene, alleles & Clinical groups & $\begin{array}{l}\text { Clinical } \\
\text { parameters }\end{array}$ & Associations & Reference \\
\hline $\begin{array}{l}\text { SNPs in IL-lbeta, } \\
\text { IL-1-receptor antago- } \\
\text { nist, IL-6, IL10, and TNF } \\
\text { alpha }\end{array}$ & $\begin{array}{l}993 \text { transplant } \\
\text { recipients and } \\
\text { their HLA-identi- } \\
\text { cal sibling donors }\end{array}$ & aGVHD & $\begin{array}{l}\text { Recipient IL10 -592A/A genotype was } \\
\text { associated with a decreased risk of } \\
\text { grade III or IV acute GVHD }\end{array}$ & \\
\hline 13 cytokine genes & $\begin{array}{l}\text {.... Recipients and } \\
\text { donors }\end{array}$ & aGVHD & $\begin{array}{l}\text { Negative association was found } \\
\text { between aGVHD and donor IL-10/GCC } \\
\text { haplotype, or donor IL-4RaA allele }\end{array}$ & $\begin{array}{l}\text { Noori-Daloii, et al., } \\
2013\end{array}$ \\
\hline $\begin{array}{l}\text { F0XP3, } \leq 15(\mathrm{GT}) \\
\text { repeats in promoter } \\
\text { region }\end{array}$ & $\begin{array}{l}252 \text { allo-matched } \\
\text { HSCT, and their } \\
\text { donors }\end{array}$ & $\begin{array}{l}\text { aGvHD, grade } \\
\text { IIIIIV }\end{array}$ & $\begin{array}{l}\text { Lower incidence of aGVHD in cases } \\
\text { of donors with } \leq 15 \text { (GT) repeats in } \\
\text { FOXP3 }\end{array}$ & Noriega et al., 2015 \\
\hline $\begin{array}{l}\text { TGF-betal codon } 10 \mathrm{TT} \text {, } \\
\text { TC and CC genotypes }\end{array}$ & $\begin{array}{l}168 \text { subjects } \\
\text { Iranian HLA- } \\
\text { matched sibling } \\
\text { BMT: donor/ } \\
\text { recipient pairs }\end{array}$ & $\begin{array}{l}\text { aGVHD } \\
\text { incidence and } \\
\text { severity }\end{array}$ & $\begin{array}{l}\text { Recipients with the T allele devel- } \\
\text { oped aGVHD significantly less than } \\
\text { those without the T allele }\end{array}$ & $\begin{array}{l}\text { Noori-Daloii et al., } \\
2007\end{array}$ \\
\hline $\begin{array}{l}\text { TLR9 (T1237C; T1486C), } \\
\text { IL23R (A1142G), and } \\
\text { N0D2 SNP8 (R702W), } \\
\text { SNP12 (G908R) and } \\
\text { SNP13 (1007fs) }\end{array}$ & $\begin{array}{l}142 \text { AML patients } \\
\text { after non-T- } \\
\text { cell-depleted } \\
\text { myeloablative } \\
\text { allo-HSCT from } \\
\text { HLA-matched } \\
\text { sibling donors }\end{array}$ & $\begin{array}{l}\text { Overall sur- } \\
\text { vival, 5-year } \\
\text { mortality, } \\
\text { aGVHD }\end{array}$ & $\begin{array}{l}\text { Donor gene variant of IL23R was } \\
\text { much less in severe aGVHD grade } \\
\text { III-IV }\end{array}$ & $\begin{array}{l}\text { Elmaagacli et al., } \\
2011\end{array}$ \\
\hline $\begin{array}{l}\text { IL-23R }(1142 A>G) \text { and } \\
\text { BPI (A645G) genes }\end{array}$ & $\begin{array}{l}304 \text { patients and } \\
\text { their donors }\end{array}$ & $\begin{array}{l}\text { aGVHD, } 0 S_{1} \\
\text { risk of relapse }\end{array}$ & $\begin{array}{l}\text { Two donor SNPs: IL-23R and BPI } \\
\text { alleles associated with less severe } \\
\text { aGVHD }\end{array}$ & $\begin{array}{l}\text { Wermke et al., } \\
2010\end{array}$ \\
\hline $\begin{array}{l}1142 \text { G>A SNP in the } \\
\text { IL-23 receptor gene } \\
\text { (IL23R) and 3 SNPs in } \\
\text { the N0D2/CARD15 gene }\end{array}$ & $\begin{array}{l}231 \text { children after } \\
\text { allo-HSCT and } \\
\text { their donors }\end{array}$ & $\begin{array}{l}\text { aGVHD } \\
\text { incidence and } \\
\text { severity }\end{array}$ & $\begin{array}{l}\text { Reduced incidence of aGVHD grade } \\
\text { II-IV in patients transplanted from a } \\
\text { donor with the IL23R SNP }\end{array}$ & Gruhn et al., 2009 \\
\hline $\begin{array}{l}\text { Fcy receptor type IIIA } \\
\text { (FCGR3A) (rs396991) }\end{array}$ & $\begin{array}{l}99 \text { allo-HSCT } \\
\text { recipients with } \\
\text { myeloid ma- } \\
\text { lignancies, and } \\
\text { their unrelated } \\
\text { donors }\end{array}$ & $\begin{array}{l}\text { TRM, OS, } \\
\text { aGVHD, CGVHD }\end{array}$ & $\begin{array}{l}\text { Recipient 158V genotype associated } \\
\text { with a reduced risk of cGVHD and } \\
\text { a trend towards a reduced risk of } \\
\text { grade II-IV acute GVHD }\end{array}$ & Takami et al., 2011 \\
\hline $\begin{array}{l}\text { SNPs in CD28, inducible } \\
\text { co-stimulator, CTLA4, } \\
\text { granzyme B, Fas and } \\
\text { Fas ligand }\end{array}$ & $\begin{array}{l}240 \text { pairs of } \\
\text { recipients and } \\
\text { donors }\end{array}$ & $\begin{array}{l}\text { GVHD, sur- } \\
\text { vival, relapse } \\
\text { risk }\end{array}$ & $\begin{array}{l}\text { Donor CTLA4 gene CT60 variant allele } \\
\text { (AA genotype) had a reduced inci- } \\
\text { dence of grades II-IV acute GVHD }\end{array}$ & Xiao et al., 2012 \\
\hline $\begin{array}{l}\text { CXCL12 gene polymor- } \\
\text { phism (rs1801157) }\end{array}$ & $\begin{array}{l}323 \text { patients and } \\
\text { donors }\end{array}$ & $\begin{array}{l}\text { Toxicity, } \\
\text { aGVHD, viral } \\
\text { reactivation }\end{array}$ & $\begin{array}{l}\text { aGvHD (grades I-IV) lower in recip- } \\
\text { ients with CXCLI2-3' A allele or AA } \\
\text { homozygous genotype }\end{array}$ & $\begin{array}{l}\text { Bogunia-Kubik et } \\
\text { al., } 2015\end{array}$ \\
\hline
\end{tabular}

One may conclude from these data that functional gene polymorphisms of immune factors/receptors associated with incidence/severity of GvHD are most commonly by donor origin. Recipient gene alleles are connected with aGVHD in few association studies. Therefore, donor cells seem mostly determine genetic background in clinical aGVHD.

A similar gene association data with GvHD reported by 2012 were statistically evaluated by Chien et al. (2012). Their own results obtained by Affymetrix arrays (genome-wide sequencing) of 1298 allogeneic transplants (both donor and patient samples) were tested to confirm previously reported candidate genes predisposing for GvHD. Of 40 previously reported candidate SNPs, 6 were successfully genotyped by the authors, and 10 other traits were added (imputed) and passed statistical criteria, thus getting association data from $>40$ studies on different polymorphic candidate genes able to influence aGvHD incidence. 
To assess relative importance of candidate genes, the authors (Chien et al., 2012) used an algorithm involving minimal allele frequency (MAF) and Hardy-Weinberg equilibrium parameters, in order to assess reliability and contribution of the given allele to GvHD occurrence. Among the tested alleles, they have selected IL-10 promoter alleles (IL10 SNPs rs1800871 and rs1800872); IL-6 promoter variant rs1800795; IL2 allele (rs2069762); rs3087243 in CTLA4, rs4364254 in HPSE, and rs1801131 in MTHFR genes. In general, the tested gene set largely corresponds to the list of informative genes revealed in our analysis (see Table 2). As a result, the rs1800795 SNP in IL6 donor genotype was associated with sufficiently increased risk for grade III-IV aGVHD following HSCT.

Surprisingly, Chien et al. (2012) have revealed very low replication rate for the candidate gene SNPs, i.e., only 7\%. Such low replication rates are encountered in early genetic literature and may result from non-standardized techniques of SNP detection, or application of formal statistical criteria.

Another class of non-MHC genes affecting HCT outcome is illustrated by the recent study by McCarroll et al. (2009) showing that deletion of the entire UGT2B17 gene determining a numer of HLA gene alleles can result in an alloimmune response associated with aGvHD. This multi-center study (1345 patients) initially examined six common deletions (UGT2B17, UGT2B28, GSTT1, GSTM1, LCE3C and OR51A2) in a phase I discovery study using 414 HLA MRD transplants. The association of the UGT2B17 deletion with acute GVHD was validated in two additional cohorts of, resp., 336 and 595 HLA-identical sibling transplants. Risk of acute GVHD proved to be greater $(O R=2.5)$ when donor and recipient were mismatched for homozygous deletion of UGT2B17.

\section{Thrombosis risk and gene polymorphism}

In the world literature some early data were published regarding probable risk of thrombotic complications postHSCT (McDonald GB et al., 1993).

Later on, a single-center study by Tunisian authors concerned incidence of central venous catheter (CVC)-related thrombosis in HSCT recipients (Abdelkefi et al., 2005). The laboratory prothrombotic markers included factor $\mathrm{V}$ Leiden, the prothrombin gene Gly20210A mutation, plasma antithrombin levels, and protein $\mathrm{C}$ and $\mathrm{S}$ activity. A total of 171 patients were included. Of them five $(2.9 \%)$ and three $(1.7 \%)$ patients had evidence of protein $\mathrm{C}$ and protein $\mathrm{S}$ deficiency, respectively. Only one patient had an antithrombin deficiency $(0.6 \%)$. In total, 10 patients $(5.8 \%)$ were heterozygous for the factor $\mathrm{V}$ Leiden mutation, and one patient had heterozygous prothrombin G20210A mutation (0.6\%). Thrombosis was diagnosed in four out of 20 patients (20\%) with a inherited prothrombotic abnormality compared to nine of 151 patients $(6 \%)$ who did not have a thrombophilic marker (relative risk 3.3 CI 95\% 1.1-9.9). These results provided a marginal evidence of inherited prothrombotic abnormalities contributing to CVC-related thrombosis in HSCT group.
Over last 2 decades, studying posttransplant effects of functional thrombophylic variants have not yielded some distinct results. E.g., a work by Azik et al. (2015) concerned patients possible correlations between venous thromboembolism (VTE) in 92 pediatric allo-HSCT patients within 100 days post-transplant. The studied prothrombotic risk factors included factor V Leiden, prothrombin G20210A, methylenetetrahydrofolate reductase (MTHFR) C677T, and MTHFR A1298C mutations; and serum homocysteine and lipoprotein(a), plasma antithrombin III, protein C, and protein $S$ levels in all patients pre-transplant. Eight patients (9\%) proved to be heterozygous for factor V Leiden, 5 (6\%) were homozygous for MTHFR 677TT, 12 (14\%) were homozygous for MTHFR 1298CC, and 2 (2\%) were heterozygous for prothrombin G20210A polymorphism. VTE was diagnosed in 5 patients (5.4\%); a prothrombotic risk variant been found in 3 of them. In summary, no significant relationship between VTE and inherited prothrombotic risk factors. Hence, an inherited prothrombotic risk for VTE after HSCT is low, but should be considered.

\section{Effects upon survival rates}

General effects of different-level gene polymorphisms upon transplant-related mortality (TRM) were recently performed by Sucheston-Campbell et al. (2015). Of course, better matching for HLA combined with supportive care and infection prophylaxis have improved survival over the past two decades. Hovewer, numerous SNP variants may lead to differential gene transcription, translation, and protein structure. These changes have the potential to modify immune responses or side effects of chemotherapy and/or radiation, and thus, survival outcomes in HCT patients.

Of those, genetic associations of NOD2/CARD15 with survival after HCT draw special attention. However, the first encouraging results was not confirmed in next studies. E.g., the largest NOD2/CARD15 study to date, 567 donor-recipient pairs both HLA matched and mismatched with primary diagnoses including hematologic malignancies, non-hematologic malignancies, and nonmalignant diseases, found only a borderline association $(\mathrm{p}=0.049)$ of a recipient SNP with increased TRM and conflicting results in the non-malignant patient groups (Kreyenberg, 2011). Some effect upon patients survival was revealed, and weak statistical correlation was found exclusively for recipient-side (SNP13) associated with increased pTRM $(<0.01)$.

As referred in abovementioned review by Sucheston-Campbell et al. (2015), many works concerned candidate genes have been tested for informative SNP associatiated with transplant-related mortality(TRM) and overall survival (OS), checking SNPs in oxidative genes (GSTM1, UGT2B17), cytokine and chemokine genes, their receptors in both donors and recipients. Numerous studies beared on receptor-mediated immune recognition (FCGR3A, CTLA4 ), and NOD2/ CARD15, like as VDR, MTHFR etc. So far, the candidate gene studies are at phase of association studies, without current clinical applications, due to their limited reproducibility. 


\section{Discussion}

Since several decades, recipient/donor HLA matching was a sine qua non condition for optimal HSCT. Transplantation of cord blood cells and HSC from haploidentical donors has changed this paradigm. By opposite, minor differences in HLA patterns are now regarded as a sufficient factor of graft-versus-leukemia effect in the patient. Moreover, HLA allelic loss (segmental chromosome 6 deletions) in leukemia clones is considered a factor of erroneous HLA typing, immune escape of tumor cells and higher relapse risk after HSCT (Taborelli et al., 2006; Dubois et al., 2012).

Moreover, a number of other functional gene variants may affect survival and risk of complications following in HSCT patients and are grouped as follows:

1. Most by recipient origin: drug metabolism-controlling genes (pharmacogenes) influencing biotransformation, time-dose kinetics and effects of cytotoxic drugs used in conditioning therapy are mostly genes expressed mostly in recipient liver, spleen and and target cells (both normal and malignant)

2. Mostly donor cell genes: cytokine genes encoding interleukins and some key inflammation regulators - mostly donor genes

3. Both recipient and donor origin: receptor and contact protein genes which encode innate receptors recognizing bacterial antigens and contacts proteins.
Key role of activated cytokine network in aGvHD genesis is widely recognized. The cytokine response seems to be switched by severe damage to normal tissues caused by conditioning therapy. At this time point, the relatively resistant innate immune cells, such as monocyte/macrophages, produce a series of inflammatory cytokines, i.e., IL-1, IL-4, IL-6, IL-12, IFN $\gamma$, TNF $\alpha$ etc. The aseptic inflammation is further enhanced by antigens from exogenous microbiota invading due to loss of epithelial integrity (Fig. 1, from Ramadan, Paczesny, 2015). The authors suggest specific induction of IL-6, IL-4, and IL-12 of, respectively, Tc17/Th17, Tc2/Th2, and Tc1/Th1 lymphocyte populations. Those, together with NK cells and monocytes/macrophages, exert cytolytic effects upon target epithelial tissues causing classical acute GvHD. We see here that the candidate genes well fit the general chain of cytokine/receptor switching in evolving inflammatory reaction underlying aGVHD.

Medical applications of these protein factors as potential therapeutic targets are confirmed by clinical trials with appropriate anticytokine monoclonal antibodies are, mostly, at Phase I/II, and their clinical significance is not yet fully assessed. Other cytokine antagonists should be tested for their efficiency to prevent aGvHD, e.g., monoclonal antibodies against gamma chains of the main cytokines. In rodent models, pharmacological blockade of TNF-a, IL-6, and $\mathrm{C}-\mathrm{C}$ chemokine receptor type 5 (CCR5) is proven to prevent aGvHD development (Teshima et al., 2016).

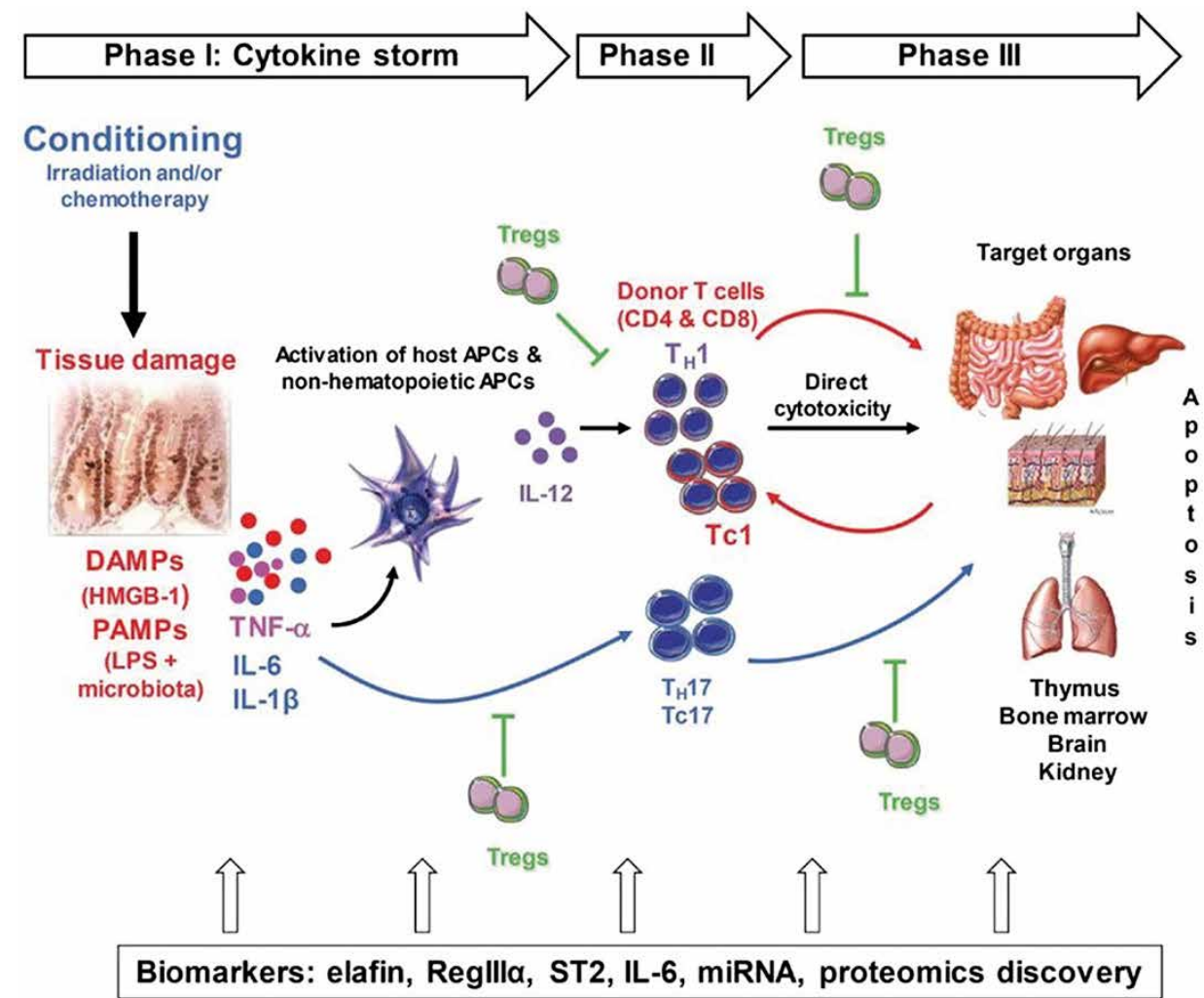

Figure 1. Pathogenesis of acute GVHD. Pre-transplant conditioning causes tissue damage. The affected tissues and cells release DAMPs (HMGB-1), PAMPs (LPS) from gut microbiota as well as inflammatory cytokines (e.g., IL-1 $\beta$, IL-6, and TNF- $\alpha$ ) contributing to the "cytokine storm." These are the first danger signals that activate host APCs, which activate and polarized donor T-cells toward pathogenic T-cells (TH1 and TH17 for CD4 and TC1, TC17 for CD8). Activated pathogenic T-cells infiltrate target organs (i.e., Gl tract, liver, skin) and amplify local tissue destruction. The presence of regulatory T-cells (Tregs) helps to reduce GVHD severity (Ramadan, Paczesny, 2015). 
As seen from current studies, intestinal damage in severe GvHD forms is caused by donor T cells which attack intestinal stem cell (ISCs) niches. The antigen-presenting cells stimulated by foreign (mismatched) HLA (minor and minor ones) enhance these events by secreting IL-1, IL-6, TNF and other inflammatory cytokines. The affected mucosal layers allow bacterial dysbiosis and invasion of intestinal microflora, thus enhancing acute inflammatory reactions (Teshima et al., 2016).

Among T cell modulators, CTLA-4 and PD-1 are now intensively studied as a possible target for immune checkpoint inhibitors (e.c., ipilimumab). The CTLA-4 (CD152) is expressed both on CD4 and CD8 T cells, being, e.g., an inhibitor of autoreactive $\mathrm{T}$ cell populations (Buchbinder, Desai, 2016). Therefore, its functional alleles were studied by several groups for their GVHD risk (see table 2). In most studies, the recipient CTLA-4 alleles, hence, surviving lymphoid cells (may be, in thymus - Buchbinder), seem to increase AGVHD risk.

The immune stimulation from intestinal microbiota is mediated by the s.c. pattern-recognizing receptors known as TLR4 and NOD receptors in mammals (Heidegger et al., 2014). Therefore, their genetic variants may also play a significant role in GvHD modification, as seen from some studies (see Table 1).

From these literature data concerning a number of polymorphic functional genes we readily see that, in most cases, aGVHD is associated with donor functional polymorphisms, as seen from Table 2.

Biological significance of donor-associated gene factors may be interpreted in terms of their cell sources and specific effects on target immune cell populations. E.g., interferon-gamma is ubiquitously produced by activated T lymphocytes, NK cells, macrophages, epithelial cells.

E.g., IL-1beta is known to be synthesized by monocytes, macrophages, neutrophils, whereas proinflammatory IL-6 is produced by monocytes, macrophages and T cells. IL23 is again secreted by monocytes and dendritic cells, like as anti-inflammatory, immunosuppressive cytokine IL10 synthesized by monocytes, T4+ and B cells. Hence, most cytokines informative for gene polymorphism and associated with aGVHD, are produced by monocytes/macrophages. The donor monocytes are renewed from the GM-CFUs within $1^{\text {st }}$ month posttransplant and settle in different tissues, transforming to macrophages in addition to residual recipient macrophages. Therefore, both recipient and donor gene variants may function early after transplant thus determining their effects on certain cytokine synthesis and GVHD development. At later terms, however, donor macrophage populations seem to prevail among resident macrophages, due to natural replacement processes. The dynamics of this process is worth of further studies.

\section{Contact and attraction molecules}

Cell adhesion and attraction molecules may be also involved into pathogenesis of posttransplant complications. E.g., Thyagarajan et al. (2013) has tested SNPs of some contact molecules (ICAM1, PECAM and SELL) in 425 recipient-donor pairs subjected to allogeneic HSCT, aiming to assess their effects upon clinical outcomes (TRM, GVHD). The rs5498 in the ICAM1 in both recipients and donors associated with a lower risk of Transplant-related mortality, however, without effect upon GVHD rates and severity.

Chemokines attracting distinct cell polulations to the inflammation site, could be also functionally polymorphic. A study by Bogunia-Kubik (2015) concerned CXCL12 (SDF-1) gene polymorphism (rs1801157) in 323 patients/donors with evaluation of total toxicity, aGVHD, and viral reactivation. Presence of the CXCL12-3' A gene variant was associated with lower grade of aGVHD, thus suggesting altered migration of hematopoietic cells to the target organs.

Moreover, migration of alloreactive cells in extracellular matrix depends on local activity of collagen-degrading enzymes (matrix metalloproteinases, MMP's).

Interestingly, in our previous studies in 111 recipient/donor pairs we have found that the more transcriptionally active allele an MMP-1 gene (-1607 2G) harbored by donor HSC is associated with more frequent aGVHD in allo-HSCT patients whereas more active MMP-1 allele in recipient reduces aGvHD frequency (Chukhlovin et al., 2003). Severe GvHD (grade II-IV) was not detected with donors negative for MMP1 2G, whereas being rather common when donors carried a $2 \mathrm{G}$ allele of MMP1 ( $0 / 16$ versus $13 / 44, \mathrm{p}=0.014)$, as seen in Fig. 2.

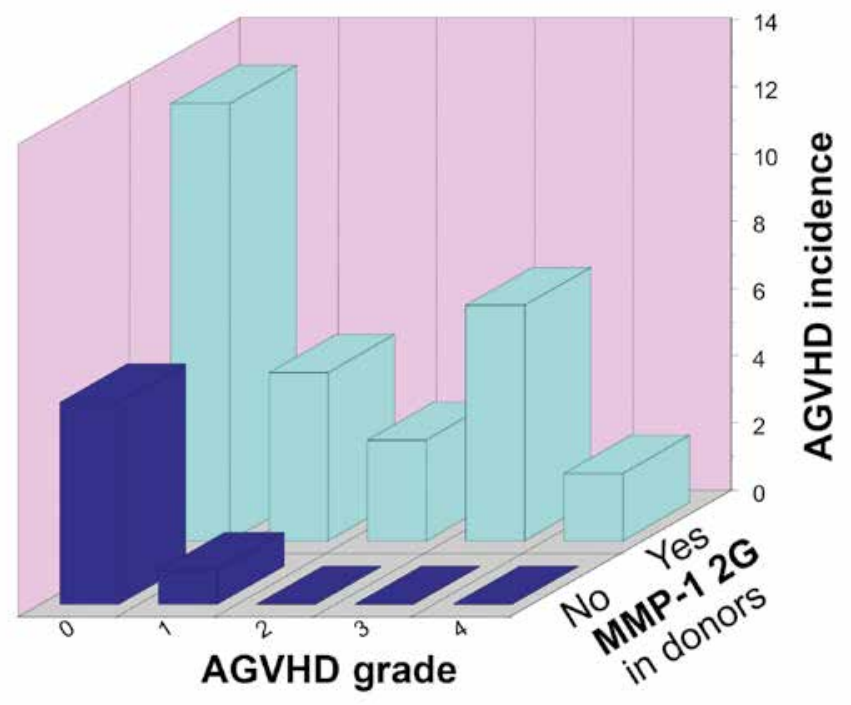

Figure 2. Increased incidence of acute GvHD in allogeneic hematopoietic transplants from donors carrying a hyperproducing MMP1 2G allele (Chukhlovin et al., 2003).

Some gene variants participating acting at cell and tissue barriers may alter basic tissue functions. For instance, one may suggest prothrombotic effects of PAI1-1 4G variant in veno-occlusive disease post HSCT, or MMP1 2G polymorphism to higher ECM permeability and easier migration of alloreactive donor lymphocytes to the target epithelium, etc. (Fig. 3). 


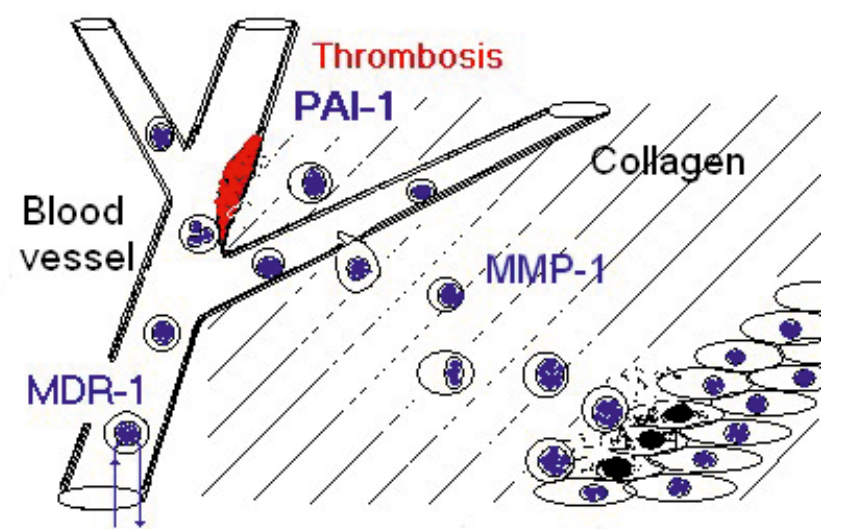

Drug flux Extracellular matrix Epithelium

Figure 3. Suggested biological effects of donor hyperactive gene variants leading to major HSCT complications.

Hence, one may suggest that active functional alleles of nonHLA genes, if present in donor cells, seem to dominate and may play a sufficient role in alloaggressive effects of donor cytotoxic T cells, thus causing severe aGVHD forms.

From Fig. 4, one may see that the local host cells (APCs) are releasing proinflammatory cytokines (TNF, IL-1, IL-6), being stimulated by damage products from cytotoxic treatment. Special affection is inflicted to intestinal wall. Death of intestinal epithelium brings about higher permeability to microbes and microbial toxins which are recognized by the NOD2 and toll-like receptors (TLRs) on the resident APCs . Their role in other complications (veno-occlusive disease, severe mucositis needs further studies.

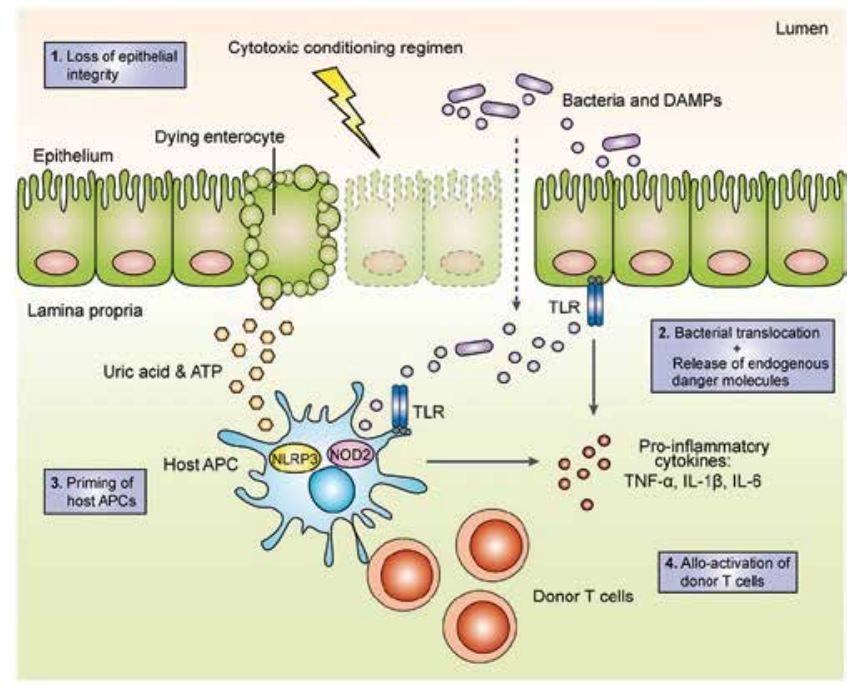

Figure 4. Schematic overview of gut bacteria-mediated initiation of acute graft-versus-host disease (Heidegger et al., 2014).

During the toxic conditioning regimen with total-body irradiation and/or chemotherapy, the destruction of intestinal epithelial cells leads to the loss of the epithelial barrier function. Similar effects occur at skin and other epithelial borders. Activated host and/or donor antigen-presenting cells prime allo-reactive donor $\mathrm{T}$ cells, which promote acute GVHD (Heidegger et al., 2014).

Most of these cytokine genes are showing informative associations showing a role of donor cells in GVHD. We cannot, of course, perform an additional donor selection for these gene variants. However, we may consider numerous non-HLA gene polymorphisms as risk factors, first of all, for AGVHD, and modify the scheduled GVHD prophylaxis regimens.

Appropriate multiplex prediction models are now developed and gradually tested, in order to personalize post-transplant preventive treatment. For example, multiple findings on donor- and recipient functional gene variants allowed of designing certain informative SNP panels for donors and recipients (Kim et al., 2012). The authors tested a group of recipients' SNPs of IL2, IL6R, FAS, EDN1, TGFB1, and NFKBIA, and donor polymorphisms of NOS1, IL1B, TGFB2, NOD2/CARD15, TNFRII, IL1R1, and FCGR2A. This selection was based on a previous big study in a total of 259 SNPs in 53 genes in 394 pairs of donors and recipients. The resulting computed risk models provided predictive stratification of the patients into low-risk (Q1), moderate-risk (Q2, Q3), and high-risk (Q4) groups with regard of OS, RFS, nonrelapse mortality $(\mathrm{P}=0.0043)$, and acute GVHD $(\mathrm{P}<0.0001)$.

\section{Conclusion}

Extensive studies are needed in order to specify distinct candidate genes for prediction of adverse pharmacological effects of cytostatic drugs in hematopoietic stem cell transplantation, covering large donor and recipient populations of various ethnicities, patient age, and different modes of hematopoietic stem cell transplants.

Modifying effects of functional gene polymorphisms, e.g., those influencing production of cytokines, adhesion and recognition molecules, are associated with incidence and severity of aGVHD. Less is known about associations of gene polymorphisms with other HSCT complications (mucositis, VOD etc.).

We have revealed some predominance in donor SNPs of immune-controlling genes associated with acute graft-versushost disease, as seen from the results of several comparative studies. This should be taken into account when planning haploidentical transplants and infusions of donor lymphoid cells in immunotherapy of tumors. For example, one may expect more expressed graft-versus-leukemia effect from the donor T cells exhibiting more active gene alleles (e.c., IL-6, IL-7R, MMP-1 et al.). By contrary, these protein products may be targeted by specific inhibitors to prevent excessive aGVHD.

Knowledge on the functional gene variants in donor may be applied for planning distinct schemes of cellular immune therapy, e.g., haploidentical HSCT, donor lymphocyte infusions, other cases of suggested graft-versus leukemia (lymphoma) effect. 


\section{Conflict of interest}

No conflict of interests is declared.

\section{References}

1. Abdelkefi A, Ben Romdhane N, Kriaa A, Chelli M, Torjman L, Ladeb S, Ben Othman T, Lakhal A, Guermazi S, Ben Hassen A, Ladeb F, Ben Abdeladhim A. Prevalence of inherited prothrombotic abnormalities and central venous catheter-related thrombosis in haematopoietic stem cell transplants recipients. Bone Marrow Transplant. 2005; 36(10):885-889.

2. Alam N, Xu W, Atenafu EG, Uhm J, Seftel M, Gupta V, Kuruvilla J, Lipton JH, Messner HA, Kim DD. Risk model incorporating donor IL6 and IFNG genotype and gastrointestinal GVHD can discriminate patients at high risk of steroid refractory acute GVHD. Bone Marrow Transplant. 2015;50(5):734-742.

3. Ambruzova Z, Mrazek F, Raida L, Stahelova A, Faber E, Indrak K, Petrek M. Possible impact of MADCAM1 gene single nucleotide polymorphisms to the outcome of allogeneic hematopoietic stem cell transplantation. Hum Immunol. 2009;70(6):457-460.

4. Arora M, Lindgren B, Basu S, Nagaraj S, Gross M, Weisdorf D, Thyagarajan B. Polymorphisms in the base excision repair pathway and graft-versus-host disease. Leukemia. 2010;24(8):1470-1475.

5. Azık F, Gökçebay DG, Tavil B, Ișık P, Tunç B, Uçkan D. Venous Thromboembolism after Allogeneic Pediatric Hematopoietic Stem Cell Transplantation: A Single-Center Study. Turk J Haematol. 2015; 32(3):228-233.

6. Berro M, Mayor NP, Maldonado-Torres H, Cooke L, Kusminsky G, Marsh SG, Madrigal JA, Shaw BE. Association of functional polymorphisms of the transforming growth factor B1 gene with survival and graft-versus-host disease after unrelated donor hematopoietic stem cell transplantation. Haematologica. 2010;95(2):276-283.

7. Bogunia-Kubik K, Middleton P, Norden J, Dickinson A, Lange A. Association of vitamin D receptor polymorphisms with the outcome of allogeneic haematopoietic stem cell transplantation. Int J Immunogenet. 2008;35(3):207-213.

8. Bogunia-Kubik K, Mizia S, Polak M, Gronkowska A, Nowak J, Kyrcz-Krzemień S, Markiewicz M, Dzierżak-Mietła M, Koclęga A, Sędzimirska M, Suchnicki K, Duda D, Lange J, Mordak-Domagała M, Kościńska K, Jędrzejczak WW, et al..Beneficial effect of the CXCL12-3'A variant for patients undergoing hematopoietic stem cell transplantation from unrelated donors. Cytokine. 2015;76(2):182-186.

9. Buchbinder EI, Desai A. CTLA-4 and PD-1 pathways: similarities, differences, and implications of their inhibition. Am J Clin Oncol. 2016; 39(1): 98-106.

10. Cao W, Xiao H, Lai X, Luo Y, Shi J, Tan Y, Zheng W, He J, Xie W, Li L, Ye X, Yu X, Lin M, Cai Z, Huang H. Genetic variations in the mycophenolate mofetil target enzyme are associated with acute GVHD risk after related and unrelated hematopoietic cell transplantation. Biol Blood Marrow Transplant. 2012;18(2):273-279.

11. Chien JW, Zhang XC, Fan W, Wang H, Zhao LP, Martin PJ, Storer BE, Boeckh M, Warren EH, Hansen JA. Evaluation of published single nucleotide polymorphisms associated with acute GVHD. Blood. 2012;119(22):5311-5319.

12. Cho IH, Song YK, Kim MG, Han N, Kim T, Oh JM. Association between interleukin-10 promoter gene polymorphisms and acute graft-versus-host disease after hematopoietic stem cell transplantation: a systematic review and meta-analysis. Hematology. 2015;20(3):121-128.

13. Choi B, Lee DE, Park HY, Jeong S, Lee SM, Ji E, Park S, Oh JM. A meta-analysis of the effects of interleukin-6 -174 G>C genetic polymorphism on acute graft-versus-host disease susceptibility. Clin Ther. 2012; 34(2):295-304.

14. Chukhlovin AB, Zabelina TS, Zubarovskaya, LS, Kroeger N, Afanasyev B.V., Zander AR., Fehse B. Association of collagenase-1 (MMP-1) gene promoter polymorphism with development of acute graft-versus-host disease in hematopoietic stem cell transplantation. Medizinskaya Immunologiya, 2003; 5(1-2), 101-106.

15. Dubois V, Sloan-Béna F, Cesbron A, Hepkema BG, Gagne K, Gimelli S, Heim D, Tichelli A, Delaunay J, Drouet M, Jendly S, Villard J, Tiercy JM. Pretransplant HLA mistyping in diagnostic samples of acute myeloid leukemia patients due to acquired uniparental disomy. Leukemia. 2012; 26(9):2079-2085.

16. Elmaagacli AH, Steckel N, Ditschkowski M, Hegerfeldt Y, Ottinger H, Trenschel R, Koldehoff M, Beelen DW. Tolllike receptor 9, NOD2 and IL23R gene polymorphisms influenced outcome in AML patients transplanted from HLA-identical sibling donors. Bone Marrow Transplant. 2011;46(5):702-708.

17. Espinoza JL, Takami A, Nakata K, Onizuka M, Kawase T, Akiyama H, Miyamura K, Morishima Y, Fukuda T, Kodera Y, Nakao S. A genetic variant in the IL-17 promoter is functionally associated with acute graft-versus-host disease after unrelated bone marrow transplantation. PLoS One. 2011;6(10):e26229. doi: 10.1371/journal.pone.0026229.

18. Franca R, Stocco G, Favretto D, Giurici N, Decorti G, Rabusin M. Role of pharmacogenetics in hematopoietic stem cell transplantation outcome in children. Int J Mol Sci. 2015;16(8):18601-18627.

19. Gan GG, Leong YC, Bee PC, Chin EF, Abdul Halim H, Nadarajan VS, Teh AK. Influence of genetic polymorphisms of cytokine genes in the outcome of HLA-matched allogeneic stem cell transplantation in a South East Asian population. Cytokine. 2016;78:55-61.

20. Goussetis E, Varela I, Peristeri I, Kitra V, Spanou K, Moraloglou O, Paisiou A, Karatasaki S, Soldatou A, Constantinidou N, Graphakos S. Cytokine gene polymorphisms and graft-versus-host disease in children after matched sibling hematopoietic stem cell transplantation: a single-center experience. Cell Mol Immunol. 2011; 8(3):276-280. 
21. Goyal RK, Lin Y, Schultz KR, Ferrell RE, Kim Y, Fairfull L, Livote E, Yanik G, Atlas M. Tumor necrosis factor-alpha gene polymorphisms are associated with severity of acute graft-versus-host disease following matched unrelated donor bone marrow transplantation in children: a Pediatric Blood and Marrow Transplant Consortium study. Biol Blood Marrow Transplant. 2010;16(7):927-936

22. Gruhn B, Intek J, Pfaffendorf N, Zell R, Corbacioglu S, Zintl F, Beck JF, Debatin KM, Steinbach D. Polymorphism of interleukin-23 receptor gene but not of NOD2/CARD15 is associated with graft-versus-host disease after hematopoietic stem cell transplantation in children. Biol Blood Marrow Transplant. 2009;15(12):1571-1577.

23. Heidegger S, van den Brink MRM, Haas T and Poeck $\mathrm{H}$ The role of pattern-recognition receptors in graft-versus-host disease and graft-versus-leukemia after allogeneic stem cell transplantation. Front. Immunol. 2014 5:337. doi: 10.3389/fimmu.2014.00337.

24. Henden AS, Hill GR. Cytokines in graft-versus-host disease. J Immunol, 2015; 194:4604-4612.

25. Holler E, Rogler G, Brenmoehl J, Hahn J, Greinix H, Dickinson AM, Socie G, Wolff D, Finke J, Fischer G, Jackson G, Rocha V, Hilgendorf I, Eissner G, Marienhagen J, Andreesen $\mathrm{R}$. The role of genetic variants of NOD2/CARD15, a receptor of the innate immune system, in GvHD and complications following related and unrelated donor haematopoietic stem cell transplantation. Int J Immunogenet. 2008;35(4-5):381384 .

26. Jaskula E, Lange A, Kyrcz-Krzemien S, Markiewicz M, Dzierzak-Mietla M, Jedrzejczak WW, Czajka P, Mordak-Domagala M, Lange J, Gronkowska A, Nowak J, Warzocha K, Hellmann A, Kowalczyk J, Drabko K, Gozdzik J, Mizia S. NOD2/CARD15 single nucleotide polymorphism 13 (3020insC) is associated with risk of sepsis and single nucleotide polymorphism $8(2104 \mathrm{C}>\mathrm{T})$ with herpes viruses reactivation in patients after allogeneic hematopoietic stem cell transplantation. Biol Blood Marrow Transplant. 2014;20(3):409-414.

27. Karabon L, Markiewicz M, Partyka A, Pawlak-Adamska E, Tomkiewicz A, Dzierzak-Mietla M, Kyrcz-Krzemien S, Frydecka I. A CT60G $>$ A polymorphism in the CTLA-4 gene of the recipient may confer susceptibility to acute graft versus host disease after allogeneic hematopoietic stem cell transplantation. Immunogenetics. 2015;67(5-6):295-304.

28. Khaled SK, Palmer JM, Herzog J, Stiller T, Tsai NC, Senitzer D, Liu X, Thomas SH, Shayani S, Weitzel J, Forman SJ, Nakamura R. Influence of Absorption, Distribution, Metabolism, and Excretion Genomic Variants on Tacrolimus/ Sirolimus Blood Levels and Graft-versus-Host Disease after Allogeneic Hematopoietic Cell Transplantation. Biol Blood Marrow Transplant. 2016;22(2):268-276.

29. Kim DD, Yun J, Won HH, Cheng L, Su J, Xu W, Uhm J, Gupta V, Kuruvilla J, Messner HA, Lipton JH. Multiple single-nucleotide polymorphism-based risk model for clinical outcomes after allogeneic stem-cell transplantation, especially for acute graft-versus-host disease. Transplantation. 2012;94(12):1250-1257.
30. Kim DH, Lee NY, Lee MH, Sohn SK. Vascular endothelial growth factor gene polymorphisms may predict the risk of acute graft-versus-host disease following allogeneic transplantation: preventive effect of vascular endothelial growth factor gene on acute graft-versus-host disease. Biol Blood Marrow Transplant. 2008;14(12):1408-1416.

31. Kreyenberg H, Jarisch A, Bayer C, Schuster B, Willasch A, Strahm B, et al. NOD2/CARD15 gene polymorphisms affect outcome in pediatric allogeneic stem cell transplantation. Blood. 2011;118(4):1181-1184.

32. Kuba A, Raida L, Mrazek F, Schneiderova P, Kriegova E, Furst T, Furstova J, Faber E, Ambruzova Z, Papajik T. ATM gene single nucleotide polymorphisms predict regimen-related gastrointestinal toxicity in patients allografted after reduced conditioning. Biol Blood Marrow Transplant. 2015;21(6):1136-1140.

33. Laverdière I, Guillemette C, Tamouza R, Loiseau P, Peffault de Latour R, Robin M, Couture F, Filion A, Lalancette M, Tourancheau A, Charron D, Socié G, Lévesque É. Cyclosporine and methotrexate-related pharmacogenomic predictors of acute graft-versus-host disease. Haematologica. 2015;100(2):275-283.

34. Lin MT, Storer B, Martin PJ, Tseng LH, Gooley T, Chen PJ, Hansen JA. Relation of an interleukin-10 promoter polymorphism to graft-versus-host disease and survival after hematopoietic-cell transplantation. $\mathrm{N}$ Engl J Med. 2003;349(23):2201-10.

35. Masetti R, Zama D, Urbini M, Astolfi A, Libri V, Vendemini F, Morello W, Rondelli R, Prete A, Pession A. Impact of inflammatory cytokine gene polymorphisms on developing acute graft-versus-host disease in children undergoing allogeneic hematopoietic stem cell transplantation. J Immunol Res. 2015;2015:248264.

36. McMillan ML, Radloff GA, Kiffmeyer WR, DeFor TE, Weisdorf DJ, Davies SM. High-producer interleukin-2 genotype increases risk for acute graft-versus-host disease after unrelated donor bone marrow transplantation. Transplantation. 2003;76(12):1758-1762.

37. McDonald GB, Hinds MS, Fisher LD, Schoch HG, Wolford JL, Banaji M, Hardin BJ, Shulman HM, Clift RA. Veno-occlusive disease of liver and multiorgan failure after bone marrow transplantation: a cohort study of 355 patients. Ann Intern Med. 1993;118:255-267.

38. Middleton PG, Norden J, Cullup H, Cavet J, Jackson GH, Taylor PR, Dickinson AM. Oestrogen receptor alpha gene polymorphism associates with occurrence of graft-versushost disease and reduced survival in HLA-matched sib-allo BMT. Bone Marrow Transplant. 2003;32(1):41-47.

39. Mullighan CG, Petersdorf EW. Genomic polymorphism and allogeneic hematopoietic transplantation outcome. Biol Blood Marrow Transplant. 2006;12(1 Suppl 1):19-27.

40. Murphy NM, Diviney M, Szer J, Bardy P, Grigg A, Hoyt R, King-Kallimanis B, Holdsworth R, McCluskey J, Tait BD. The effect of folinic acid on methylenetetrahydrofolate reductase polymorphisms in methotrexate-treated allogeneic hematopoietic stem cell transplants. Biol Blood Marrow Transplant. 2012;18(5):722-730. 
41. Nguyen Y, Al-Lehibi A, Gorbe E, Li E, Haagenson M, Wang T, Spellman S, Lee SJ, Davidson NO. Insufficient evidence for association of NOD2/CARD15 or other inflammatory bowel disease-associated markers on GVHD incidence or other adverse outcomes in T-replete, unrelated donor transplantation. Blood. 2010;115(17):3625-3631.

42. Noori-Daloii MR, Rashidi-Nezhad A, Izadi P, Hossein-Nezhad A, Sobhani M, Derakhshandeh-Peykar P, Alimoghaddam K, Ghavamzadeh A. Transforming growth factor-betal codon 10 polymorphism is associated with acute GVHD after allogenic BMT in Iranian population. Ann Transplant. 2007;12(4):5-10.

43. Noori-Daloii MR, Jalilian N, Izadi P, Sobhani M, Rabii-Gilani Z, Yekaninejad MS. Cytokine gene polymorphism and graft-versus-host disease: a survey in Iranian bone marrow transplanted patients. Mol Biol Rep. 2013;40(8):48614867.

44. Norén E, Verma D, Söderkvist P, Weisselberg T, Söderman J, Lotfi K, Almer S. Single Nucleotide Polymorphisms in MORC4, CD14, and TLR4 Are Related to Outcome of Allogeneic Stem Cell Transplantation. Ann Transplant. 2016;21:56-67.

45. Noriega V, Martínez-Laperche C, Buces E, Pion M, Sánchez-Hernández N, Martín-Antonio B, Guillem V, Bosch-Vizcaya A, Bento L, González-Rivera M, Balsalobre $P$ et al.The Genotype of the donor for the (GT)n polymorphism in the promoter/enhancer of FOXP3 is associated with the development of severe acute GVHD but does not affect the GVL effect after myeloablative HLA-identical allogeneic stem cell transplantation. PLoS One. 2015;10(10):e0140454. doi: 10.1371/journal.pone.0140454.

46. Orrù S, Orrù N, Manolakos E, Littera R, Caocci G, Giorgiani G, Bertaina A, Pagliara D, Giardini C, Nesci S, Locatelli F, Carcassi C, La Nasa G. Recipient CTLA- $4^{\star}$ CT60-AA genotype is a prognostic factor for acute graft-versus-host disease in hematopoietic stem cell transplantation for thalassemia. Hum Immunol. 2012;73(3):282-286.

47. Ostrovsky O, Shimoni A, Rand A, Vlodavsky I, Nagler A. Genetic variations in the heparanase gene (HPSE) associate with increased risk of GVHD following allogeneic stem cell transplantation: effect of discrepancy between recipients and donors. Blood. 2010;115(11):2319-2328.

48. Petersdorf EW, Malkki M, Hsu K, Bardy P, Cesbron A, et al. The International Histocompatibility Working Group in hematopoietic cell transplantation. Int J Immunogenet. 2013; 40(1): 10.1111/iji.12022.

49. Picard N, Bergan S, Marquet P, van Gelder T, Wallemacq P, Hesselink DA, Haufroid V.

50. Pharmacogenetic Biomarkers Predictive of the Pharmacokinetics and Pharmacodynamics of Immunosuppressive Drugs. Ther Drug Monit. 2016;38, Suppl 1:S57-69.

51. Ramadan A, Paczesny S. Various forms of tissue damage and danger signals following hematopoietic stem-cell transplantation. Front. Immunol. 2015; 6:14. doi: 10.3389/ fimmu.2015.00014
52. Rashidi-Nezhad A, Azimi C, Alimoghaddam K, Ghavamzadeh A, Hossein-Nezhad A, Izadi P, Sobhani M, Noori-Daloii AR, Noori-Daloii MR. TGF-Beta codon 25 polymorphism and the risk of graft-versus-host disease after allogenic hematopoietic stem cell transplantation. Iran J Allergy Asthma Immunol. 2010;9(1):1-6.

53. Resende RG, Abreu MH, de Souza LN, Silva ME, Gomez RS, Correia-Silva Jde F. Association between IL1B (+3954) polymorphisms and IL- $1 \beta$ levels in blood and saliva, together with acute graft-versus-host disease. J Interferon Cytokine Res. 2013 ;33(7):392-7.

54. Rocha V, Porcher R, Fernandes JF, Filion A, Bittencourt H, Silva W Jr, Vilela G, Zanette DL, Ferry C, Larghero J, Devergie A, Ribaud P, Skvortsova Y, Tamouza R, Gluckman E, Socie G, Zago MA. Association of drug metabolism gene polymorphisms with toxicities, graft-versus-host disease and survival after HLA-identical sibling hematopoietic stem cell transplantation for patients with leukemia. Leukemia. 2009;23(3):545-556.

55. Sellami MH, Bani M, Torjemane L, Kaabi H, Ladeb S, Ben Othmane T, Hmida S. Effect of donor CTLA-4 alleles and haplotypes on graft-versus-host disease occurrence in Tunisian patients receiving a human leukocyte antigen-identical sibling hematopoietic stem cell transplant. Hum Immunol. 2011;72(2):139-143.

56. Shamim Z, Spellman S, Haagenson M, Wang T, Lee SJ, Ryder LP, Müller K. Polymorphism in the interleukin-7 receptor-alpha and outcome after allogeneic hematopoietic cell transplantation with matched unrelated donor. Scand J Immunol. 2013; 78(2): 214-220.

57. Sivula J, Turpeinen H, Volin L, Partanen J. Association of IL-10 and IL-10Rbeta gene polymorphisms with graft-versus-host disease after haematopoietic stem cell transplantation from an HLA-identical sibling donor. BMC Immunol. 2009 May 4;10:24. doi: 10.1186/1471-2172-10-24.

58. Stark GL, Dickinson AM, Jackson GH, Taylor PR, Proctor SJ, Middleton PG. Tumour necrosis factor receptor type II $196 \mathrm{M} / \mathrm{R}$ genotype correlates with circulating soluble receptor levels in normal subjects and with graft-versus-host disease after sibling allogeneic bone marrow transplantation. Transplantation. 2003;76(12):1742-1749.

59. Sucheston-Campbell LE, Clay A, McCarthy PL, Zhu Q, Preus L, Pasquini M, Onel K, Hahn T. Identification and utilization of donor and recipient genetic variants to predict survival after HCT: are we ready for primetime? Curr Hematol Malig Rep. 2015;10(1):45-58.

60. Sugimoto K, Murata M, Onizuka M, Inamoto Y, Terakura S, Kuwatsuka Y, Oba T, Miyamura K, Kodera Y, Naoe T. Decreased risk of acute graft-versus-host disease following allogeneic hematopoietic stem cell transplantation in patients with the 5,10-methylenetetrahydrofolate reductase 677TT genotype. Int J Hematol. 2008;87(5): 451-458.

61. Taborelli M, Tibiletti MG, Martin V, Pozzi B, Bertoni F, Capella C. Chromosome band 6q deletion pattern in malignant lymphomas. Cancer Genet Cytogenet. 2006 Mar;165(2):106-113. 
62. Takami A, Espinoza JL, Onizuka M, Ishiyama K, Kawase T, Kanda Y, Sao H, Akiyama H, Miyamura K, Okamoto S, Inoue M, Ohtake S, Fukuda T, Morishima Y, Kodera Y, Nakao S; Japan Marrow Donor Program. A single-nucleotide polymorphism of the $\mathrm{Fc} \gamma$ receptor type IIIA gene in the recipient predicts transplant outcomes after HLA fully matched unrelated BMT for myeloid malignancies. Bone Marrow Transplant. $2011 ; 46(2): 238-243$.

63. Tanabe T, Yamaguchi N, Matsuda K, Yamazaki K, Takahashi S, Tojo A, Onizuka M, Eishi Y, Akiyama H, Ishikawa J, Mori T, Hara M, Koike K, Kawa K, Kawase T, Morishima Y, Amano H, Kobayashi-Miura M, Kakamu T, Nakamura Y, Asano S, Fujita Y. Association analysis of the NOD2 gene with susceptibility to graft-versus-host disease in a Japanese population. Int J Hematol. 2011;93(6):771-778.

64. Teshima T, Reddy P, Zeiser R. Acute graft-versus-host disease: novel biological insights. Biol Blood Marrow Transplant. 2016 Jan;22(1):11-6.

65. Thyagarajan B, Jackson S, Basu S, Jacobson P, Gross MD, Weisdorf DJ, Arora M. Association between genetic variants in adhesion molecules and outcomes after hematopoietic cell transplants. Int J Immunogenet. 2013;40(2):108-115.

66. Tseng LH, Storer B, Petersdorf E, Lin MT, Chien JW, Grogan BM, Malkki M, Chen PJ, Zhao LP, Martin PJ, Hansen JA. IL10 and IL10 receptor gene variation and outcomes after unrelated and related hematopoietic cell transplantation. Transplantation. 2009;87(5):704-710.

67. van der Velden WJ, Netea MG, de Haan AF, Huls GA, Donnelly JP, Blijlevens NM. Role of the mycobiome in human acute graft-versus-host disease. Biol Blood Marrow Transplant. 2013 Feb;19(2):329-32.
68. Viel DO, Tsuneto LT, Sossai CR, Lieber SR, Marques SB, Vigorito AC, Aranha FJ, de Brito Eid KA, Oliveira GB, Miranda EC, de Souza CA, Visentainer JE. IL2 and TNFA gene polymorphisms and the risk of graft-versus-host disease after allogeneic haematopoietic stem cell transplantation. Scand J Immunol. 2007;66(6):703-710.

69. Wermke M, Maiwald S, Schmelz R, Thiede C, Schetelig J, Ehninger G, Bornhäuser M, Wassmuth R. Genetic variations of interleukin-23R (1143A $>$ G) and BPI (A645G), but not of NOD2, are associated with acute graft-versus-host disease after allogeneic transplantation. Biol Blood Marrow Transplant. 2010;16(12):1718-1727.

70. Zhu P, Xie L, Yang Y, Wang J, Gong F, Fang M. IL-10 promoter polymorphism associated with decreased risk of aGvHD after stem cell transplantation: a meta-analysis. Int J Hematol. 2013;98(1):102-11.

71. Xiao HW, Lai XY, Luo Y, Shi JM, Tan YM, He JS, Xie WZ, Li L, Zhu XL, Zhu JJ, Sun J, Wei GQ, Jin L, Liu LZ, Wu KN, Yu XH, Cai Z, Lin MF, Ye XJ, Huang H. Relationship between TNFA, TNFB and TNFRII gene polymorphisms and outcome after unrelated hematopoietic cell transplantation in a Chinese population. Bone Marrow Transplant. 2011;46(3):400-407.

72. Xiao H, Luo Y, Lai X, Fu S, Shi J, Tan Y, He J, Xie W, Zheng W, Wang LM, Zhang L, Liu L, Ye X, Yu X, Cai Z, Lin M, Huang $\mathrm{H}$. Genetic variations in T-cell activation and effector pathways modulate alloimmune responses after allogeneic hematopoietic stem cell transplantation in patients with hematologic malignancies. Haematologica. 2012;97(12):18041812. 


\title{
Помимо HLA-системы: риск иммунных осложнений аллотрансплантации гемопоэтических стволовых клеток зависит от функциональных не-HLA аллелей донорского происхождения
}

\author{
Алексей Б. Чухловин \\ НИИ детской онкологии, гематологии трансплантологии им. Р. Горбачевой Первого Санкт-Петербургского \\ государственного медицинского университета им. И. П. Павлова, Санкт-Петербург, Россия
}

\section{Резюме}

Эта обзорная статья касается генетической предрасположенности к ряду тяжелых иммунных осложнений при аллогенной трансплантации гемопоэтических стволовых клеток (алло-ТГСК), которые зависят в основном от различий донора и реципиента по набору системы HLA и так называемым минорным факторам совместимости, например определенным аллелям HLA-G и другим белкам иммунной системы (TNF- $\alpha$, IL1- $\beta$, IL-2, -6, 10) и их рецепторам, что связано с общей выживаемостью, возможным отторжением трансплантата или острой реакцией «трансплантат против хозяина» (оРТПХ). Кроме того, ТГСК является сложной процедурой с применением множества цитотоксических агентов, применяемых при кондиционирующей терапии, а также иммуносупрессивных препаратов, используемых после ТГСК. Минимальные различия в нуклеотидных последовательностях ряда функционально активных генов могут вызвать значительные различия в уровнях повреждения клеток и их восстановления после ТГСК. Эти полиморфные аллели могут повысить или снизить биологическое действие различных энзимов, рецепторов, молекул-транспортеров, факторов транскрипции ДНК и т.д. Поэтому конкретные полиморфные генные аллели, проявляющие высокую или низкую активность, могут быть ассоциированы с основными осложнениями ТГСК и выживаемостью реципиентов. Имеющиеся данные о многочисленных эффектах полиморфизмов не-HLA-генов в парах «донор-реципиент» позволил нам сделать следующие выводы: 1) функционально активные гены, контролирующие метаболизм препаратов, используемых при кондиционирующей терапии, были, в основном, генами реципиента, которые экспрессируются, главным образом, в печени, селезенке и кроветворных клетках-мишенях химиотерапии; 2) наибольший интерес представило преобладание эффекта генов донорского происхождения, ассоциированных с оРТПХ, по сравнению с малым влиянием аналогичных аллелей реципиентов ТГСК.

Это преимущество эффектов донорских аллелей следует принимать во внимание при планировании гаплоидентичных трансплантаций и инфузий лимфоидных клеток донора при иммунотерапии злокачественных новообразований. Например, можно ожидать большей экспрессии эффекта «трансплантат против лейкоза» при введении донорских Т-клеток, несущих более активные аллели ряда генов (например, IL-6, IL-7R, MMP-1 и др.). Напротив, эти белки могут быть мишенью соответствующих таргетных препаратов с целью предотвращения тяжелых форм оРТПХ.

\section{Ключевые слова}

Трансплантация гемопоэтических клеток, исходы, функциональные полиморфизмы генов, иммунные осложнения, фармакокинетика. 